\title{
Sport accidents in childhood
}

\author{
Y. Sahlin, MD
}

Emergency Clinic, Regional and University Hospital, Trondheim, Norway

\begin{abstract}
Injuries among children during sporting activities are common. This study is a one year study including children between five and fourteen years of age who sustained their injuries during sporting activities and were treated at Trondheim Regional and University Hospital.

Sport accidents account for 27 per cent of all childhood accidents in this age group. Fifty-three per cent of the injured were boys, and 47 per cent were girls. The boys sustained more severe injuries than the girls. Soccer caused the greatest number of injuries. Horse riding and alpine skiing were the cause of the most severe injuries.

A more widespread use of protective guards, better technique and body control, better coaching and not allowing the younger children to take part in technically advanced sporting activities might reduce the number and the severity of the sport injuries in children.
\end{abstract}

Keywords: Injuries, children, sport, study

\section{Introduction}

Sport is an engaging and enjoyable activity for children and adolescents. The participation in both organized and recreational sport starts at preschool age. The children, their parents, the physical education teachers and the coaches seem to accept the risk of injury as an unavoidable part of sport participation ${ }^{1}$.

Most studies of sport related injuries have focused on the incidence rate in adults ${ }^{2-4}$. A few authors have studied childhood accidents in sport and accidental risks in non-organized and organized sporting activities ${ }^{1,5-7}$.

The aim of this study was to identify risk factors, in different age groups and different types of sport, in relation to equipment, sport arenas and children's behaviour which could influence the number of accidents and the severity of the injuries. Based on these risk factors, preventive measures are proposed.

\section{Materials and methods}

All patients admitted to the Regional and University Hospital at Trondheim, as a result of an accident, from June 1985 to June 1986, were recorded. Trondheim is a regional hospital with a primary catchment area of about 200000 inhabitants. The inpatients as well as the

Address for correspondence: Dr Y. Sahlin, Emergency Clinic, Regional and University Hospital, Trondheim, Norway

(C) 1990 Butterworth \& Co (Publishers) Ltd 0306-3674/90/010040-05

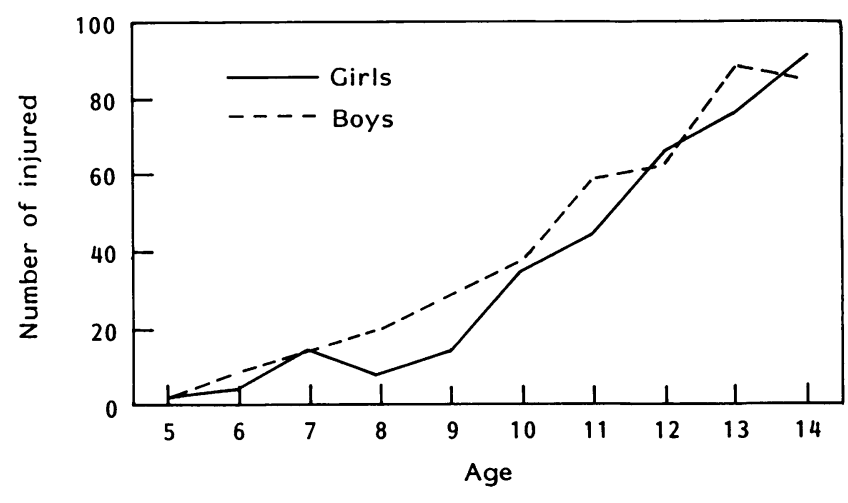

Figure 1. Distribution of sport injuries according to age and gender

outpatients were registered. Children from five to fourteen years old were given a questionnaire which was filled out by the injured or their companions on arrival in the hospital. Bicycle accidents were only identified as sports accidents if they occurred during cycle training or competition. Playground accidents were only identified as sport accidents if a sport activity was practised on the playground.

Each patient was identified as one case even if they had more than one injury. Information on each patient including personal data, when, where and how the accident occurred, when they arrived in the hospital, the body part injured, the diagnoses, the treatment, the severity of the injury, the number of consultations, the number of days in hospital and the degree of permanent disability at the time of discharge from hospital were collected and analysed.

An accident was defined as a sudden external occurrence leading to a personal injury which required medical care. The injury must not be more than one month old at the first visit to the hospital. The AIS code (AIS, 76) was used for grading the severity of the injuries. The chi-square test and the student $t$-test (twotail) were used for statistical analysis. p-values below 0.05 were regarded as significant.

\section{Results}

During the year of study, 2841 children were recorded as injured, with 27 per cent ( 758 children) of these sustaining their injuries during sporting activities. Thirtynine per cent of the injured were below the age of 12 years and 61 per cent were 12 years old or older. The distribution of gender was the same in all age groups; 47 per cent of the injured were girls, and 53 per cent were boys (Figure 1). 
Table 1. Distribution of injured girls and boys according to type of sport

\begin{tabular}{|c|c|c|c|c|}
\hline \multirow[b]{2}{*}{ Sport activity } & \multicolumn{4}{|c|}{ Number of injured } \\
\hline & Girls & Boys & & tal \\
\hline $\begin{array}{l}\text { Soccer } \\
\text { Handball } \\
\text { Alpine skiing } \\
\text { Cross country skiing } \\
\text { Ball, unspecified } \\
\text { Gymnastics } \\
\text { Ice skating } \\
\text { Horse riding } \\
\text { Ice hockey } \\
\text { Judo/karate } \\
\text { Skijumping } \\
\text { Swimming } \\
\text { Volleyball/basketball } \\
\text { Roller skating } \\
\text { Other } \\
\text { Track }\end{array}$ & $\begin{array}{r}47 \\
106 \\
25 \\
22 \\
24 \\
21 \\
21 \\
20 \\
1 \\
4 \\
1 \\
8 \\
12 \\
2 \\
38 \\
5\end{array}$ & $\begin{array}{r}131 \\
18 \\
61 \\
42 \\
16 \\
19 \\
7 \\
3 \\
11 \\
8 \\
13 \\
9 \\
6 \\
1 \\
51 \\
3\end{array}$ & $\begin{array}{r}178 \\
124 \\
86 \\
64 \\
40 \\
40 \\
28 \\
23 \\
12 \\
12 \\
14 \\
17 \\
18 \\
3 \\
91 \\
8\end{array}$ & $\begin{array}{r}24 \% \\
16 \% \\
11 \% \\
8 \% \\
5 \% \\
5 \% \\
4 \% \\
3 \% \\
2 \% \\
2 \% \\
2 \% \\
2 \% \\
2 \% \\
1 \% \\
12 \% \\
1 \%\end{array}$ \\
\hline Total & $35947 \%$ & $39953 \%$ & 758 & $100 \%$ \\
\hline
\end{tabular}

Table 2. Distribution of mechanisms of injury and severity

\begin{tabular}{|c|c|c|c|c|c|}
\hline Type of sport & Falling & $\begin{array}{l}\text { Falling } \\
\text { from heights }\end{array}$ & Collision & Other & Total \\
\hline $\begin{array}{l}\text { Soccer } \\
\text { Handball } \\
\text { Alpine skiing } \\
\text { Skiing } \\
\text { Ball, unspecified } \\
\text { Gymnastics } \\
\text { Ice hockey and ice skating } \\
\text { Horse riding } \\
\text { Other }\end{array}$ & $\begin{array}{l}66 \\
42 \\
66 \\
55^{*} \\
11 \\
11 \\
21 \\
2^{*} \\
53\end{array}$ & $\begin{array}{c}1^{*} \\
2 \\
3 \\
0 \\
2 \\
14 \\
0 \\
12^{*} \\
17\end{array}$ & $\begin{array}{r}101 \\
76 \\
16 \\
7 \\
44 \\
14 \\
13 \\
6 \\
39\end{array}$ & $\begin{array}{r}9 \\
4 \\
1 \\
2 \\
1 \\
1 \\
8 \\
3 \\
35\end{array}$ & $\begin{array}{c}178 \\
124 \\
86 \\
64^{*} \\
58 \\
40 \\
40 \\
23^{*} \\
145\end{array}$ \\
\hline $\begin{array}{l}\text { Total } \\
*=\text { Mean AIS > } 1.5\end{array}$ & $311(41 \%)$ & $51(11 \%)$ & $314(41 \%)$ & $52(7 \%)$ & $758(100 \%)$ \\
\hline
\end{tabular}

Soccer was the most common cause of injury. Among girls, handball was the sport leading to the greatest number of accidents (Table 1). In this study the older children sustained more injuries than the younger children. Softball, swimming and ice skating were the only activities with a higher percentage of injured below the age of 12 years.

Collision with other objects or other persons accounted for 41 per cent of the accidents. Falling from heights accounted for 11 per cent of the accidents (Table 2). The mechanism of the injury followed the same pattern when the older and younger children and the two sexes were compared. The older children were more often injured in collision accidents with other persons than the younger children. There was no difference in severity of the collision accidents according to age. The injuries caused by falling were significantly more severe than the collision accidents in all age groups and in both sexes $(p<0.05)$.

The upper extremities were the most common body part injured (Table 3). There was no difference in severity between the different body parts injured. Fractures were as common as sprains in the upper extremities. Sprains were the most common cause of injury in trauma to the lower extremities. Contusions were the most common cause of head injuries. Sprain in the upper extremity was the most common diagnosis, and fracture of the forearm was the most common type of fracture (Table 4).

There were no fatal injuries. There was no difference in severity according to age. Alpine skiing and horse riding caused the greatest number of severe injuries (according to AIS). The boys sustained significantly more severe injuries than girls. Two children with epidural haematomas now both suffer from reduced brain function. They were the only two discharged from hospital with permanent disability.

Ten per cent of the injured required hospitalization. Mean hospitalization time was six days (range 1-60 d, median $2 \mathrm{~d}$ ). There was no difference in mean age between the inpatients and the outpatients. Cross country skiing, alpine skiing and soccer led to the highest number of hospital admission. The horse riding, track and cross country accidents had the highest per cent- 
Table 3. Distribution of types of injuries according to sport and injury severity

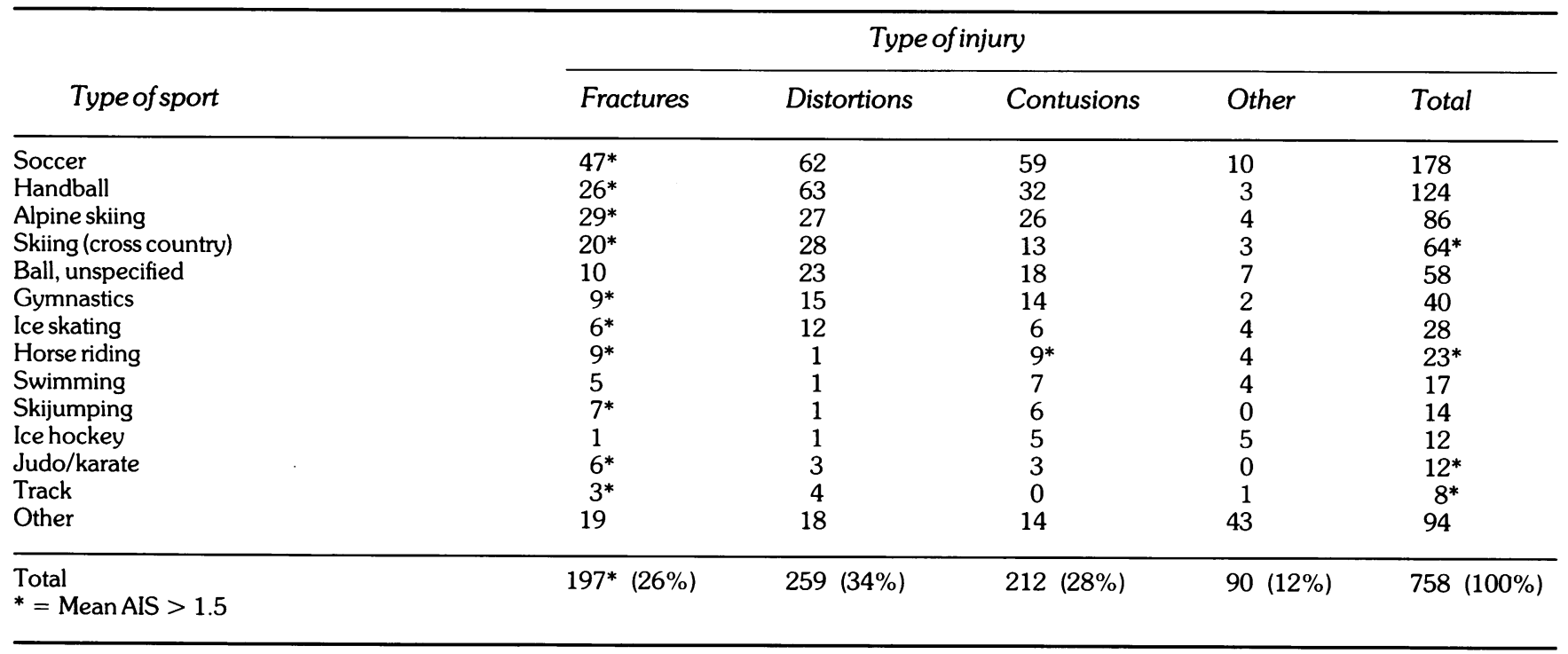

Table 4. Distribution of diagnoses according to age

\begin{tabular}{|c|c|c|c|}
\hline \multirow[b]{2}{*}{ Diagnosis } & \multicolumn{3}{|c|}{ Number of injuries } \\
\hline & $5-11$ years old & $12-14$ years old & Total \\
\hline $\begin{array}{l}\text { Sprain, overextension } \\
\text { Sprain, underextension } \\
\text { Contusion/laceration, under extension } \\
\text { Contusion/laceration, over extension } \\
\text { Contusion/laceration, head } \\
\text { Forearm fracture } \\
\text { Hand/finger fracture } \\
\text { Contusion/laceration, other } \\
\text { Ankle/foot fracture } \\
\text { Tibia/fibula fracture } \\
\text { Concussion } \\
\text { Humerus fracture } \\
\text { Rib/clavicle fracture } \\
\text { Head/face fracture } \\
\text { Femur fracture } \\
\text { Dislocation, other } \\
\text { Epidural haematoma } \\
\text { Dislocation, hip } \\
\text { Dislocation, overextension } \\
\text { Sprain, others }\end{array}$ & $\begin{array}{r}44 \\
49 \\
40 \\
25 \\
32 \\
30 \\
10 \\
17 \\
10 \\
11 \\
9 \\
3 \\
6 \\
0 \\
4 \\
2 \\
2 \\
0 \\
0 \\
0\end{array}$ & $\begin{array}{r}82 \\
76 \\
58 \\
59 \\
30 \\
31 \\
45 \\
18 \\
18 \\
9 \\
10 \\
8 \\
4 \\
6 \\
1 \\
2 \\
1 \\
2 \\
2 \\
2\end{array}$ & $\begin{array}{r}126 \\
125 \\
98 \\
84 \\
62 \\
61 \\
55 \\
35 \\
28 \\
20 \\
19 \\
11 \\
10 \\
6 \\
5 \\
4 \\
3 \\
2 \\
2 \\
2\end{array}$ \\
\hline Total & 294 & 464 & 758 \\
\hline
\end{tabular}

age of hospital admission. The injured required an average of 1.7 medical consultations (range 1-9, median 1).

\section{Discussion}

This study is not an incidence study. The incidence of children's sport accidents is difficult to determine due to problems in defining the population at risk. Soccer, for example, is a very popular activity, especially among younger boys. They practice soccer whenever and wherever they get the opportunity. A calculation of the time at risk or the population at risk would give vague figures. These facts are supported by Tursz et al. ${ }^{7}$.

In the present study, the sport accidents accounted for 27 per cent of the childhood accidents. In the Tursz et al. study the sport injuries represented only 11 per cent of all childhood accidents ${ }^{7}$. Our percentages are similar to the percentage which Jacobson et al. found in their Swedish study ${ }^{8}$. In other studies, not only are the injuries requiring medical care registered ${ }^{9,10}$, but they also include the minor injuries treated by the coaches or the school nurses. This makes a comparison of the distribution of injury severity and accident occurrence in the different sporting activities difficult.

Sporting activities, as well as sport accidents, are more common among older children. An important fact is that the sport accidents sustained by younger children are just as severe and follow the same mechanism of injury as those sustained by older children. The younger children are not as well trained and have poorer body control than the older children ${ }^{6,10,11}$. We still do not have enough knowledge of why this is 
so, either in the high skilled sporting activities, or in the sporting activities that do not require a high skill performance. More research is required in this field.

Sport activity is the only type of activity where girls sustain the same percentage of injuries as boys ${ }^{12}$. The relatively high number of injuries among girls may be due to the fact that girls receive less qualified coaching and less technical advice compared to boys ${ }^{1,6,13}$.

The distribution of different types of sport in this study is different from other studies on the same topic ${ }^{1,9,14-16}$. In these American studies, football is the main source of sport injury. Since we do not play American football in this part of the world, the results are bound to be different. Therefore, there is need for national data.

A notable group of accidents are the swimming accidents. None of the swimming accidents occurred during swimming itself, but by slipping on the floor in the swimming pool area or shower room. A different type of floor might reduce these accidents. No submersion accidents were registered. Neither did we record any diving accidents. Diving accidents account for between four and 14 per cent of all spinal cord injuries among adolescents according to Bruce et al. ${ }^{17}$.

The number of accidents during handball are surprisingly high. Handball is very popular in this part of the country and the number of accidents reflects the high numbers participating in this sport.

The use of protective guards may reduce the severity of sport accidents ${ }^{18}$. The use of shin guards are already required in soccer tournaments in this country. In the present study, three children sustained tibial fractures; two of these occurred during school activities. Shin guards are not required in school soccer play, in practice or in school tournaments. By making this mandatory, the number of tibial fractures in soccer may be diminished.

The severity of the sport injuries and the percentage requiring hospitalization follow the same pattern as childhood accidents in general ${ }^{12}$. The most severe injuries in this study were intra-cranial bleeding. They were life threatening events and led in two out of three cases to permanent disability. They occurred in horse riding, alpine skiing and handball activities. The one handball player who sustained an epidural haematoma slipped on the floor. This has not been described as a common cause of injury ${ }^{19}$ and may be due to unpreventable accident.

The epidural haematoma sustained in alpine skiing and horse riding is well known type of accident ${ }^{20-22}$. The severe head injuries in alpine skiing as well as in horse riding might be reduced by using protective helmets ${ }^{20,22,23}$. The fact that minor head injuries in children are not leading to any sequelae stresses even more the importance of using a helmet $t^{24}$.

It is too early to grade the degree of permanent disability, especially in fractures of long bones, when the child is discharged from hospital because of growth disturbance and epiphyseal fractures. MacDonald states that most epiphyseal injuries are benign in relation to growth disturbances ${ }^{6}$.

\section{Conclusions}

Sport accidents are common and could be reduced in number and severity by implementing the following proposals:

Mandatory use of protective equipment such as helmets and shin guards

Provision of more skilled coaches

Increased practice in general training, leading to better body control, especially among young children

Preventing younger children from participating in technically advanced sporting activities

Further research to acquire more knowledge on the mechanisms of injury according to age and technical skill.

\section{Acknowledgement}

This study was supported by grants from SørTrøndelag county. The author would like to thank Prof. Inggard Lereim, Trine M. Stene and Per Balstad for helpful suggestions.

\section{References}

1 Zaricznyj, B., Shttuck, M., Mast, T., Robertson, R. and Elia, G. Sport-related injuries in school-aged children Am J Sports Med 1980, 5, 318-324

2 Johnson, R. and Ettlinger, C. Alpine ski injuries: Changes through the years Clin Sports Med 1982, 1, 181-197

3 Pettrone, F. and Ricciadelli, E. Gymnastic injuries: The Virginia experience 1982-1983 Am J Sports Med 1987, 1, 59-62

4 DeHaven, K. and Lintner, D. Athletic injuries: Comparison by age, sport, and gender Am J Sports Med 1986, 3, 218-224

5 Garrick, J. Sports medicine Pediatric Clinics of North America 1986, 6, 1541-1550

6 MacDonald, G. Sports injuries in children Postgrad Med 1985, 1, 279-289

7 Tursz, A. and Crost, M. Sport-related injuries in children Am J Sports Med 1986, 4, 294-299

8 Jacobson, B., Bek-Jensen, H. and Jansson, B. One year's incidence of school accidents and their severity in a Swedish municipality Scand J Prim Health Care 1986, 4, 213-217

9 Garrick, J. and Requa, R. Injuries in high school sports Pediatrics 1978, 3, 465-469

10 Austin, G., Rogers, K. and Reese, G. Injuries in high school physical education classes Am J Dis Child 1980, 134, 456-458

11 Goldberg, B., Rosenthal, P., Robertson, L. and Nicholas, J. Injuries in youth football Pediatrics 1988, 2, 255-261

12 Lereim, I. and Sahlin, Y. Barneulykker Tidskr. Nor. Lægeforen 1984, 31, 2155-2158

13 Nilsson, S. and Roaas, A. Soccer injuries in adolescents Am J Sports Med 1978, 6, 358-361

14 Gerberich, S., Priest, J., Boen, J., Straub, C. and Maxwell, $\mathrm{R}$. Concussion incidence and severity in secondary school varsity football players $\mathrm{Am} \mathrm{J}$ of Publ Health $1983,12,1370-1375$

15 Kraus, J. and Conroy, C. Mortality and morbidity from injuries in sports and recreation Ann Rev Public Health 1984, 5, 163-192

16 Mueller, F. and Blyth, C. Epidemiology of sports injuries in children Clin in Sports Med 1982, 3, 343-352

17 Bruce D., Schut, L. and Sutton, L. Brain and cervical spine injuries occurring during organized sports activities in children and adolescents Clin in Sports Med 1982, 3, 495-514 
18 Sandelin, J. Acute sports injuries requiring hospital care Brit J Sports Med 1986, 3, 99-102

19 Jørgensen, U. Epidemiology of injuries in typical Scandinavia teamsports Br J Sports Med 1984, 2, 59-63

20 Oh, S. and Schmid, U. Kindliche Kopfverletzungen beim Skifahren und ihre optimale Prophylaxe Z Kinderchir 1983, 38, 66-72

21 Moreland, M. Skiing injuries in children Clin in Sports Med 1982, 2, 241-251
22 Montgomery, M. and Tordai, P. Galopp under traning vanligaste olyckstillfallet vid ridolyckor bland barn Lakartidningen 1986, 42, 3488-3489

23 Nygren, A., Tingvall, C. and Gustavsson, H. Epidemiology of head injuries in Sweden Acta Neurochir 1986, $36,10-12$

24 Rutter, M., Chadwick, O., Shaffer, D. and Brown, G. A prospective study of children with head injuries: Design and methods Psychol Med 1980, 10, 633-645 